\title{
Treatment Outcome of Métaizeau Technique of Intramedullary Pinning in Pediatric Displaced Radial Neck Fracture
}

\author{
Karki $\mathrm{P}^{1}$, Ranabhat $\mathrm{R}^{2}$, Shah $\mathrm{A}^{1}$
}

\section{ABSTRACT}

Introduction: Displaced radial neck fracture in children when poorly managed results in deformity of elbow and incapacitates patient's daily activities due to compromised forearm motion, hence they require careful attention. Aim: The aim of this study is to assess the outcome of Métaizeau Technique in displaced radial neck fracture in Children. Methods: This hospital based study evaluated the treatment outcome of 35 patients with an average age of 9.34 years (range, $6-14$ years), who presented with displaced radial neck fracture; and were treated by Métaizeau technique of intramedullary pinning by Kirschners (K) wire at Nepalgunj Medical College, Kohalpur from April 2017 to January 2020. Only Judet's type 3 and 4 fractures were included in this study. Close reduction was attempted in all cases. All patients were followed up for an average of 8.4 months (range, 6-12 months). Functional outcome was assessed as per Métaizeau functional score. Results: All fractures united at an average of 3.770 .84 months (meanSD). Twenty seven patients had type 3 fracture and remaining 8 had type 4a fracture. Twenty five (92.5\%) patients with type 3 fracture exhibited excellent results; while three patients (37.5\%) with type 4a fracture had excellent outcome. Closed reduction produced excellent outcome in all patients while $80.95 \%$ patients with percutaneous reduction had excellent result. Conclusion: Outcome depends on initial fracture type and mode of reduction. Closed reduction should be preferred over an open reduction in order to achieve superior outcome.

Keywords: Intramedullary nailing, Métaizeau technique, Pediatric radial neck fracture, Percutaneous reduction.

Authors:

1. Dr. Prateek Karki

2. Dr. Roshani Ranabhat

3. Dr. Aman Shah

${ }^{1}$ Department of Orthopedics, Nepalgunj Medical College and Teaching Hospital, Kohalpur, Banke

${ }^{2}$ Department of Radiology, Nepalgunj Medical College and Teaching Hospital, Kohalpur, Banke

\section{Address for Correspondence:}

\author{
Dr. Prateek Karki \\ Department of Orthopedics \\ Nepalgunj Medical College and Teaching Hospital \\ Kohalpur, Banke, Nepal \\ Email: prateekkarki@gmail.com
}

\section{INTRODUCTION}

Radial neck fracture accounts for 5 to $10 \%$ of fractures around elbow in children. ${ }^{1}$ The injury may happen with fall in an outstretched hand with elbow in extension and valgus or rarely associated with an elbow dislocation. ${ }^{2,3}$ In both the mechanism, the force which is transmitted through the proximal radial epiphysis concentrate over neck region hence causes a fracture there. ${ }^{3}$

Judet $^{4,5}$ has classified radial neck fracture based on degree of angulation (table I). Those displaced less than 30 degrees can be managed with posterior splints for one to two weeks. ${ }^{6}$ Those angulated more than 30 degrees or severely displaced fractures needs reduction. Open reduction however is discouraged in these injuries, as it may lead to complications like avascular necrosis (AVN) of radial epiphysis, premature closure of the epiphysis or an intra-articular calcification. However, it is reserved only for those fractures that remains significantly angled or displaced even after multiple attempts with closed reduction or minimally invasive techniques have failed. Therefore, for severely angulated fractures a postreduction residual angulation less than 30 degrees has a benefit over risk in an attempt to achieve anatomical reduction by open reduction introducing further soft tissue trauma. ${ }^{6}$

This study aims towards functional and radiographic evaluation of Judet's type 3 and type 4 radial neck fractures managed with an intramedullary Kirschners (K) wire fixation by technique as described by Métaizeau ${ }^{7}$, preferably by close reduction or with the help of a percutaneous K-wire leverage. Open reduction was reserved only for those fractures that cannot be reduced even after minimally invasive percutaneous leverage. 
This surgery helps in anchorage of small proximal fragment with adequate stability without violating elbow joint, so that elbow movement can be started early. The surgery is simple and does not require a steep learning curve. Implant removal is also an outpatient procedure making the treatment cheap. This Study aims to assess the functional and radiological outcome in displaced radial neck fracture in Children.

\begin{tabular}{|cc|}
\hline Judet's Classification & Degree of angulation \\
\hline Type 1 & Undisplaced \\
\hline Type 2 & $<30$ degrees \\
\hline Type 3 & $30-60$ degrees \\
\hline Type 4a & $60-80$ degrees \\
\hline Type 4b & $>80$ degrees \\
\hline
\end{tabular}

Table I : Judet's classification of pediatrics radial neck fracture ${ }^{4,5}$

\section{METHODS}

This prospective observational study consists of 35 pediatric patients with displaced radial neck fracture who were taken as convenient sampling technique at Nepalgunj Medical College Teaching Hospital, Kohalpur, Nepal from April 2017 to January 2020 and were managed with an intramedullary K-wire by Métaizeau technique.

Informed written consent was taken from the patient's guardian and only those willing to take part in this study were included.

\section{Inclusion criteria:}

1. Age between 6 years to 14 years

2. Angulation more than 30 degree at fracture site.

3. Open growth plates of the elbow at the time of injury.

\section{Exclusion criteria:}

1. Open fracture.

2. Age more than 14 years and less than 6 years

3. Pathological fracture

\section{Surgical technique}

Under general anesthesia or brachial block patient was placed supine with injured limb over a hand table draped from axilla to hand. Approximately $2 \mathrm{~cm}$ longitudinal incision was made just about $2 \mathrm{~cm}$ proximal to the distal radial physis under fluoroscopy, along lateral radial border. After meticulous dissection of soft tissues to avoid injury to superficial sensory branch of radial nerve, a hole was made by a bone awl over lateral cortex. A $2.0 \mathrm{~mm} \mathrm{~K}$-wire with its sharp tip angulated almost 20 to 30 degrees; which was bent about $1.5 \mathrm{~cm}$ from its tip was introduced through the portal of entry. The wire was gently advanced till its tip reached the fracture site.

Close reduction was attempted in all cases with traction in extension of elbow and varus stress with surgeons thumb pressing over radial head as described by Patterson. ${ }^{8}$ If the reduction was successful (radial neck- shaft angle was reduced to $<30$ degrees and displacement of bone fragments less than $30 \%)$, then the K-wire with bent tip was advanced into the proximal fragment and was rotated 180 degree after engaging into proximal epiphysis, as described by Métaizeau. ${ }^{7}$ If close reduction was unsuccessful then the displaced radial head was manipulated with a $2 \mathrm{~mm}$ K-wire percutaneously under fluoroscopy as described by Böhler. ${ }^{9} \mathrm{After}$ successful reduction, the intramedullary K- wire was inserted in previously described technique and the percutaneous $\mathrm{K}$ - wire was removed.

In some displaced fractures where the reduction could not be achieved even after minimally invasive technique, an open reduction was carried out with Kocher approach. ${ }^{10}$ Approximately $5 \mathrm{~mm}$ of the lower end of intramedullary $\mathrm{K}$ wire was slightly bent and was left outside skin for removal after the fracture consolidates. Postoperatively an above elbow slab was applied for two weeks. After removal of plaster, elbow was gently mobilized.

Patients were followed up at regular intervals at two weeks, four weeks, eight weeks, 12 weeks post operatively and then every two months from six months to one year. At the final follow up, flexion and extension of elbow and pronation and supination of the forearm were measured by a goniometer while the contralateral elbow served as a control. Functional recovery of elbow was assessed according to Métaizeau functional score., 7 Final radiographs of elbow in anteroposterior and lateral views were used to evaluate any residual angulation. ${ }^{11}$ It was measured by an angle subtended by a line drawn perpendicular to the articular surface and long axis of radial shaft and results were documented as table II:

\begin{tabular}{ll}
$\begin{array}{c}\text { Radiological } \\
\text { outcome }\end{array}$ & Residual angulation at fracture site \\
\hline Excellent & If the reduction was anatomic \\
\hline Good & If a simple shift or inclination not exceeding $20^{\circ}$ persisted \\
\hline Fair & If the tilt was between $20^{\circ}$ and $40^{\circ}$ \\
\hline Poor & If the tilt was beyond 40 \\
\hline
\end{tabular}

Table II : Radiological outcome after pediatric radial head fracture ${ }^{11}$

\section{Statistical analysis}

All statistical analysis was performed using SPSS version 25 . $\mathrm{P}<0.05$ was considered statistically significant. Pearson chisquare test was used to analyze functional outcome according to classification of fracture and type of reduction during surgery. Mean and standard deviation were calculated for all measured and calculated values.

\section{RESULTS}

We included 35 patients ( 21 male and 14 female) with an average age of 9.34 years (range, $6-14$ years) meeting the inclusion criteria. The patients were followed for an average 
of 8.4 months (range, 6-12 months). All fractures united at an average of 3.770 .84 months (meanSD), following which the K-wire was removed at outpatient basis (figure 1 showing sequential follow up).

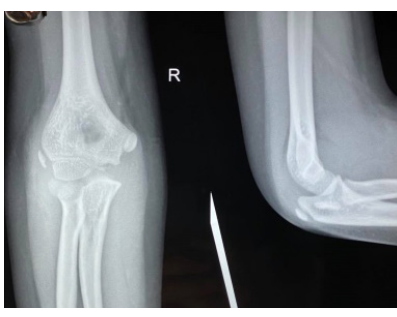

Before surgery

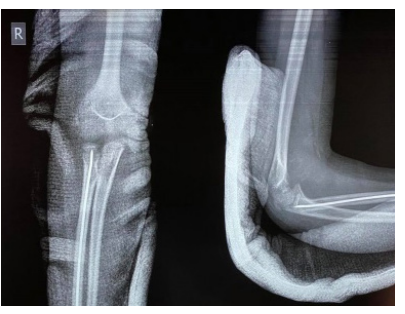

After 2 weeks

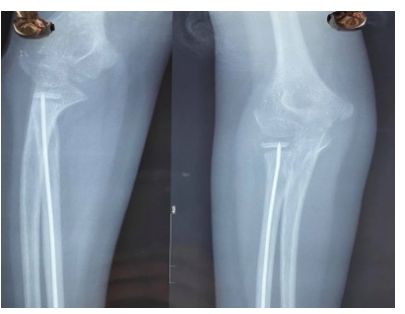

8 week follow up

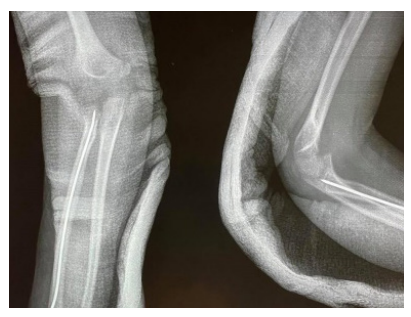

Immediate Postoperative

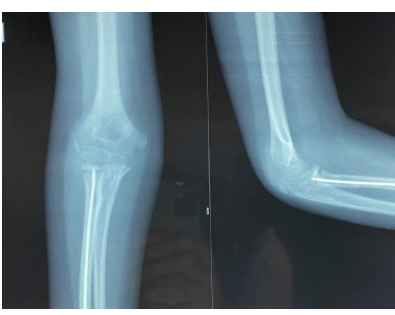

4 week follow up

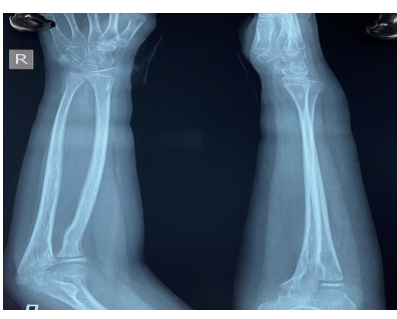

Final follow up
Figure 1 : Sequential radiograph till final follow-up

27 patients sustained fall while playing and remaining 8 had fallen from a tree. There were 27 type 3 fractures among which close reduction was possible in 11 patients (40\%) while the remaining 16 fractures (60\%) were reduced by means of a percutaneous leverage. Eight patients had type 4a, among which percutaneous reduction was done in 5 (62\%) patients while 3 (38\%) patients underwent an open reduction (table III).

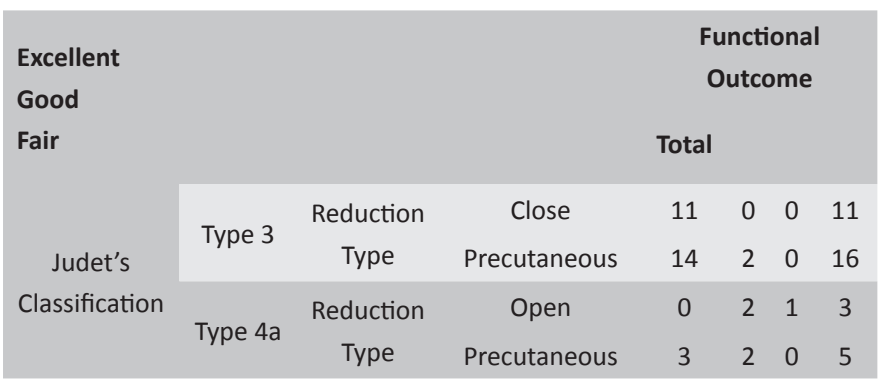

Table III: Functional outcome in relation with type of fracture and method of reduction used

The initial fracture pattern had statistically significant influence over the functional outcome. Less severe displacement was associated with a better functional outcome. Out of 27 patients with type 3 fracture, 25 (92.5\%) had an excellent result; while among those with type 4a fracture, only 3 (37.5\%) had excellent result, $\mathrm{p}$ value 0.002 (table III).

Similarly, the type of reduction also had significant impact with functional outcome. All patients who underwent a close reduction had excellent functional outcome while only $80.95 \%$ patients with percutaneous reduction showed similar result and none of the patients with an open reduction exhibited excellent result, $p=0.001$. However, those patients who required an open reduction had some degree of limitations in their elbow and forearm range movements. Out three patients in open reduction group two had good functional result and one had fair result (table IV).

\begin{tabular}{llcccc}
\multicolumn{2}{c}{ Close } & \multicolumn{3}{c}{ Type of reduction } & Total \\
\cline { 3 - 4 } & Excellent & 11 & 17 & 0 & 28 \\
Functional & Good & 0 & 4 & 2 & 6 \\
outcome & Fair & 0 & 0 & 1 & 1 \\
Total & & 11 & 21 & 3 & 35
\end{tabular}

Table IV : Relation between type of reduction and functional outcome

One patient had neuropraxia of radial nerve following an open reduction, that later recovered after three months. Treatment outcomes in associated fractures were satisfactory (table V).

\begin{tabular}{ccccc} 
Associated injuries & Treatment method & \multicolumn{2}{c}{ Functional outcome } \\
$\begin{array}{c}\text { Medial epicondyle } \\
\text { fracture }\end{array}$ & Conservative & 0 & 1 & 0 \\
$\begin{array}{c}\text { Olecranon fracture } \\
\begin{array}{c}\text { Undisplaced ulna } \\
\text { fracture }\end{array}\end{array}$ & $\begin{array}{c}\text { Tension band wiring } \\
\text { Close reduction and } \\
\text { intramedullary fixation }\end{array}$ & 0 & 2 & 0 \\
& 1 & 0 & 0
\end{tabular}

Table $V$ : Treatment outcome in associated fractures

The radiological outcome in final follow up was excellent in 20 (57.14\%) and good in 15 (42.86\%) patients (figure 2).

Pie chart showing radiological outcome at final follow up

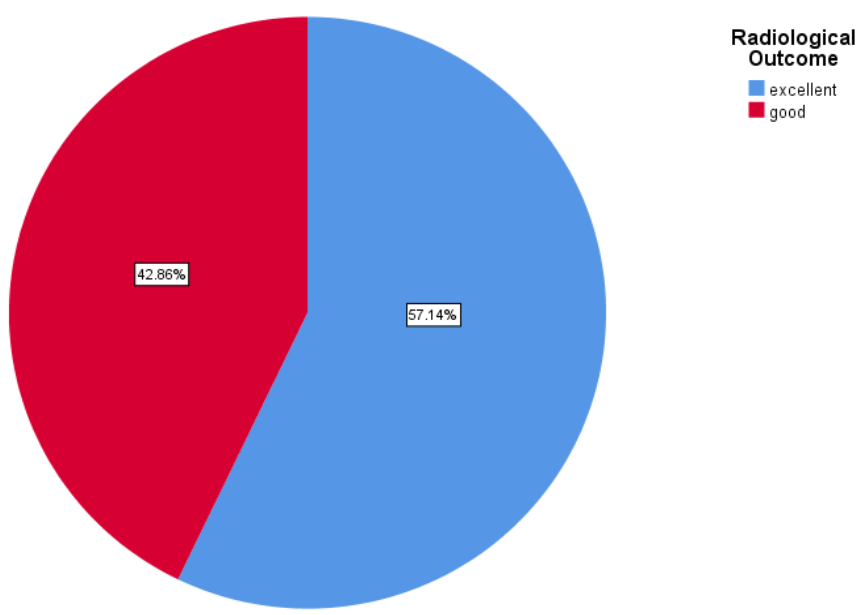

Figure 2 : Radiological outcome 


\section{DISCUSSION}

Fracture usually occurs at radial neck region by indirect mechanism when the patient falls on an outstretched hand with elbow in extension and valgus. ${ }^{3}$ The cartilaginous radial head in children are more resistant to fracture as compared to the radial neck.

The treatment options for radial neck fractures are widely determined by the radial neck-shaft angle. Un-displaced or minimally displaced fractures (Judet's type 1 and 2 respectively) can be successfully treated conservatively by an above elbow cast in neutral position or slight pronation for 2 to 3 weeks. ${ }^{6,12}$ Tachdjian's $^{6}$ and Métaizeau et al $^{7}$ have proposed angulation more than 30 degrees does not remodel and result in subsequent loss of forearm motion, hence the angulation should be corrected by surgery. In our study, we included only cases with angulation more than 30 degrees. These acceptable angulation limits are consistent with that of Zang et $\mathrm{al}^{1}$, Ursei et $\mathrm{al}^{11}$ and Wang et al. ${ }^{13}$ An optimal treatment option for displaced fracture is still controversial. Several studies reported the functional outcome of close reduction and minimally invasive percutaneous leverage to be similar. ${ }^{14}$, ${ }^{15}$ In children cartilaginous radial head receives its blood supply from metaphysis, which may be impaired during fracture. This vascular insult may further attenuate during an open reduction leading to complications like avascular necrosis or premature fusion of physis. Hence an open reduction is widely criticized by several authors. ${ }^{1,7,16,17}$ Bernstein et al. ${ }^{18}$ specifically reported poor functional outcome despite of a desirable perioperative reduction after an open reduction. Therefore we also reserved an open reduction in only those cases which remained angulated more than 30 degrees after closed reduction.

In our study closed reduction maneuver with varus stress as described by Patterson ${ }^{8}$, was possible in 11 cases. Excellent result was obtained in all patients which was comparable to that of D'souza et al. ${ }^{16}$ Of 21 cases where a K- wire was used percutaneously to lever and reduce the fracture, 17 patients had excellent outcome (81\%) while remaining four patients exhibited good outcome. The result was encouraging and was consistent with that of Zang et al $^{1}$ and Ursei et al. ${ }^{11}$

Three patients, where fracture was severely angulated (Judet's type 4) underwent an open reduction. One patient had 30 degree loss of motion as compared to normal side and was considered as fair result as per Métaizeau functional score 4,7 while the remaining two had less than 20 degrees loss of motion exhibiting good result. All fracture united, which was not an issue however, those patients who underwent an open reduction landed with decreased elbow range of motion. The results were comparable with Zhang et al. ${ }^{1}$ One patient with type 4a fracture where an open reduction was carried out, developed neuropathy of posterior interosseous nerve, which spontaneously recovered after 3 months. This patient had 20 degree loss of elbow motion arc and 10 degrees loss of supination of affected forearm which was documented as fair result as per Métaizeau functional score.4, 7 Ugutmen et $\mathrm{al}^{2}$ reported chance of damage to physis during $\mathrm{K}$-wire manipulation however, in our study we could not find any difference in functional outcome between patients treated with close reduction or with the help of percutaneous leverage, result was not statistically significant $p>0.005$. Our result were consistent with that of Al-Aubaidi et $\mathrm{al}^{19}$ and Wang et al. ${ }^{13}$

\section{LIMITATIONS}

The sample size is smaller so that total numbers of patients were not enough to make more accurate conclusion but considering rarity of these fractures it is still a case series with adequate number. Another limitation is lack of control group to compare this technique with conservative management or plating to make a more meaningful conclusion.

\section{CONCLUSION}

We conclude that close reduction and percutaneous reduction are superior to an open reduction. Hence an open reduction can be avoided to pursue endeavour of achieving an anatomical reduction. The surgery is easy, cheap and implant removal can be done at an outpatient basis.

\section{REFERENCES}

1. Zhang FY, Wang XD, Zhen YF, Guo ZX, Dai J, Zhu LQ. Treatment of severely displaced radial neck fractures in children with percutaneous K-wire leverage and closed intramedullary pinning. Medicine. 2016 Jan;95(1).

2. Ugutmen E, Ozkan K, Ozkan FU, Eceviz E, Altintas F, Unay K. Reduction and fixation of radius neck fractures in children with intramedullary pin. Journal of Pediatric Orthopaedics B. $2010 \mathrm{Jul}$ $1 ; 19(4): 289-93$.

3. O'BRIEN PI. Injuries involving the proximal radial epiphysis. Clinical Orthopaedics and Related Research ${ }^{\circledR} .1965$ Jul 1; 41:51-8.

4. Schmittenbecher PP, Haevernick B, Herold A, Knorr P, Schmid E. Treatment decision, method of osteosynthesis, and outcome in radial neck fractures in children: a multicenter study. Journal of Pediatric Orthopaedics. 2005 Jan 1; 25(1):45-50.

5. Judet J, Judet R, Lefranc J. Fracture of the radial head in the child. InAnnales de chirurgie 1962 Sep (Vol. 16, p. 1377).

6. Herring JA. Tachdjian's pediatric orthopaedics: from the Texas Scottish Rite Hospital for children. Elsevier Health Sciences; 2013 Dec 2.

7. Metaizeau JP, Lascombes P, Lemelle JL, Finlayson D, Prevot J. Reduction and fixation of displaced radial neck fractures by closed intramedullary pinning. Journal of Pediatric Orthopaedics. 1993 May 1; 13(3):355-60.

8. Patterson RF. Treatment of displaced transverse fractures of the neck of the radius in children. JBJS. 1934 Jul 1; 16(3):695-8. 
Karki et al.: Treatment Outcome of Métaizeau Technique of Intramedullary Pinning in Pediatric Displaced Radial Neck Fracture

9. Bohler J. Conservative treatment of fractures of the radial neck.

Der Chirurg; Zeitschrift fur alle Gebiete der operativen Medizen. 1950 Dec;21(12):687.

10. Bartoníček J, Naňka O, Tuček M. Kocher approach to the elbow and its options. Rozhledy v chirurgii: mesicnik Ceskoslovenske chirurgicke spolecnosti. 2015 Oct; 94(10):405-14.

11. Ursei M, De Gauzy JS, Knorr J, Abid A, Darodes P, Cahuzac J. Surgical treatment of radial neck fractures in children by intramedullary pinning. Acta orthopaedica belgica. 2006 Apr; 72(2):131.

12. Jain ${ }^{1} \mathrm{~N}$, Kulshrestha ${ }^{1}$ A. Treatment of Displaced Fracture Neck Radius In Children By Closed Reduction Using K-Wire And Percutaneous Intramedullary Pinning. Journal of Bone and Joint Diseases Jan-June. 2017 Jan; 32(1):14-7.

13. Wang J, Chen W, Guo M, Su Y, Zhang Y. Percutaneous reduction and intramedullary fixation technique for displaced pediatric radial neck fractures. Journal of Pediatric Orthopaedics B. 2013 Mar 1; 22(2):127-32.

14. Gutiérrez-de la Iglesia D, Pérez-López LM, Cabrera-González M, Knörr-Giménez J. Surgical techniques for displaced radial neck fractures: predictive factors of functional results. Journal of Pediatric Orthopaedics. 2017 Apr 1; 37(3):159-65.

15. Steinberg EL, Golomb D, Salama R, Wientroub S. Radial head and neck fractures in children. Journal of pediatric orthopedics. 1988; 8(1):35-40.

16. D'souza S, Vaishya R, Klenerman L. Management of radial neck fractures in children: a retrospective analysis of one hundred patients. Journal of pediatric orthopedics. 1993; 13(2):232.

17. Basmajian HG, Choi PD, Huh K, Sankar WN, Wells L, Arkader A. Radial neck fractures in children: experience from two level-1 trauma centers. Journal of Pediatric Orthopaedics B. 2014 Jul 1; 23(4):369-74.

18. Bernstein SM, McKeever P, Bernstein L. Percutaneous reduction of displaced radial neck fractures in children. Journal of Pediatric Orthopaedics. 1993 Jan 1; 13(1):85-8.

19. Al-Aubaidi Z, Pedersen NW, Nielsen KD. Radial neck fractures in children treated with the centromedullary Metaizeau technique. Injury. 2012 Mar 1; 43(3):301-5. 